\title{
Fluid perfused urethral pressure profilometry and Valsalva leak point pressure: a comparative study in a biophysical model of the urethra
}

\author{
Tim Idzenga $\cdot$ Johan J. M. Pel $\cdot$ Ron van Mastrigt
}

Received: 23 January 2007 / Accepted: 4 May 2007 / Published online: 19 June 2007

(C) Springer-Verlag 2007

\begin{abstract}
In patient studies the correlation between maximum urethral closure pressure (MUCP) and Valsalva leak point pressure (LPP) is meagre at best $(r=0.22-0.50)$. We therefore studied the relation between MUCP and LPP in a flexible and extensible model urethra. We applied differently sized pressure zones and different degrees of resistance to a biophysical model urethra by stepwise inflating three types of blood pressure cuff placed around the model. At each degree of resistance we measured detrusor LPP, an in vitro equivalent of Valsalva LPP. Subsequently, we recorded the Urethral Pressure Profile using a water-perfused $5 \mathrm{~F}$ end-hole catheter at four withdrawal rates and five perfusion rates and calculated MUCP. We tested the dependence of LPP on pressure zone length and MUCP on perfusion rate, withdrawal rate and pressure zone length using analysis of variance. We tested the correlation between LPP and MUCP using Pearson's correlation coefficient and Linear Regression. LPP did not significantly depend on the pressure zone length $(P=0.80)$ and increased linearly with increasing cuff pressure. MUCP also increased with increasing cuff pressure, however, MUCP significantly depended $(P<0.01)$ on perfusion rate, withdrawal rate and pressure zone length. MUCP increased with increasing perfusion rate, and decreased with increasing withdrawal rate. In our model urethra MUCP only accurately reflected urethral resistance for a very limited number of combinations of perfusion rate and withdrawal rate. LPP reflected urethral resistance independent of the type of pressure zone.
\end{abstract}

T. Idzenga $(\varangle) \cdot$ J. J. M. Pel · R. van Mastrigt Department of Urology, Erasmus MC, Sector Furore, room EE1630, PO Box 2040, 3000 CA Rotterdam, The Netherlands e-mail: t.idzenga@erasmusmc.nl
Keywords Urethral pressure profile $\cdot$ Maximum urethral closure pressure $\cdot$ Leak point pressure $\cdot$ Polyvinyl alcohol . Model urethra

\section{Introduction}

Leak point pressure (LPP) and urethral pressure profilometry (UPP) are both methods that aim at measuring the maximum bladder pressure the urethra can withstand without leakage [1]. With LPP the intravesical pressure is increased by either increasing the abdominal pressure (Valsalva manoeuvre or coughing) or the detrusor pressure. When leakage is visually observed the intravesical pressure is noted as LPP [1]. With UPP pressure along the urethra is recorded, starting in the bladder. The maximum difference between urethral and bladder pressure is denoted as the maximum urethral closure pressure (MUCP) [1].

The two most frequently used techniques to perform UPP in the clinic are micro-tip transducers and fluid perfused catheters with side-/end-hole. Micro-tip transducers are very sensitive and give good quality recordings. However, they are expensive and fragile [2], require proper positioning in the urethra $[3,4]$ and are prone to artefacts caused by the sensor touching the urethral wall [5]. Also micro-tip transducers are found to have a larger standard deviation in measuring MUCP than fluid perfused catheters [6]. Fluid perfused catheters are inexpensive, disposable and easy to use in the clinic, although care must be taken to prevent air bubbles. Artefacts may be induced by motion, and the signals of fluid perfused catheters with side-holes depend on rotational positioning in the urethra. An endhole catheter eliminates this problem and is therefore considered the best fluid perfused catheter for performing a UPP-measurement [3]. Reproducibility of the UPP-method 
is poor, which is possibly caused by lack of standardisation of the procedure [7]. Using the perfusion technique, the investigator has to choose catheter type, perfusion rate and withdrawal rate of the catheter. Perfusion rates between 2 and $5 \mathrm{ml} / \mathrm{min}$ and withdrawal rates between 2 and $7 \mathrm{~mm} / \mathrm{s}$ have been reported in the literature [8-12]. The correlation between UPP and Valsalva LPP has been studied in female patients with stress urinary incontinence. It was found that the correlation was meagre at best $(r=0.22-0.50)$ [13-15]. It was also found that contraction and relaxation of pelvic floor muscles influence UPP [16]. Valsalva LPP measurements on the other hand depend on the vesical volume [17, 18], catheter size [19] and patient position [20]. Also the time-delay between observation of leakage and pressure recording affects the LPP.

Many studies on the correlation between MUCP and LPP have been done in patients. Measurements in patients can easily vary. Therefore we objectively compared the two measurement techniques in a 'static' urethra, a flexible and collapsible urethral model made from polyvinyl alcohol (PVA). We developed this urethral model to study perineal recording of noise as a non-invasive diagnostic method for diagnosing bladder outlet obstruction. In a separate study we confirmed a relation between this recorded noise and the degree of prostatic obstruction in the model [21]. Three types of inflatable blood-pressure cuffs placed around the model and inflated stepwise, simulated three different types of pressure zones. We measured detrusor LPP at different cuff pressures by increasing the pressure at the entrance of the urethral model until leakage was observed. The pressure at which leakage occurred may be considered a quasi-static approximation of the Valsalva LPP. In this paper it will be denoted LPP. We performed UPP at five different perfusion and four different withdrawal rates and calculated MUCP.

\section{Materials and methods}

We made a flexible and distensible model urethra by pouring a $10 \%$ aqueous solution of PVA into a cylindrical mould with a diameter of $16 \mathrm{~mm}$ and a length of $150 \mathrm{~mm}$. To create a channel allowing flow through the model, we placed a strip with a Y-profile (with legs $5 \mathrm{~mm}$ wide) along the central axis of the mould (see Fig. 1). After $6 \mathrm{~h}$ of rest at room temperature $\left(21^{\circ} \mathrm{C}\right)$, the mould was stored in a freezer at $-20^{\circ} \mathrm{C}$. After $14 \mathrm{~h}$ in the freezer the mould was stored at room temperature for $10 \mathrm{~h}$. This freeze-thaw cycle was repeated three times. The urethral model had viscoelastic properties comparable to the male pig urethra [22]. It was placed approximately $1 \mathrm{~cm}$ below the water level in a water-filled container to prevent dehydration of the PVA.

Three types of inflatable blood pressure cuffs were placed around the model as three different types of pressure

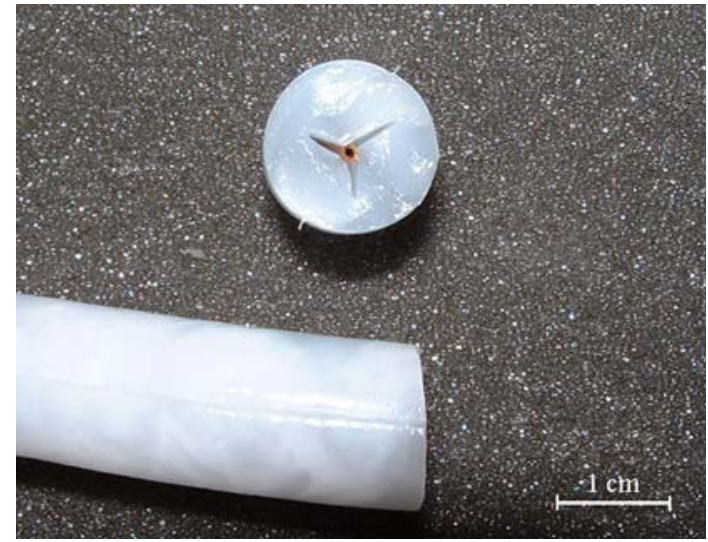

Fig. 1 Cross-section and side view of a PVA model urethra with a Y-shaped channel to allow flow through the model

zones. A $28 \mathrm{~mm}$ wide single cuff (Tricomed, EME Ltd., Brighton, UK) represented a relatively short pressure zone. A sequence of two of these Tricomed-cuffs represented a relatively long zone. The third pressure zone was a $55 \mathrm{~mm}$ wide single cuff (Critikon 5, Johnson \& Johnson Medical Inc., Arlington, VA, USA), thus creating a second relatively long zone. The cuffs were inflated to pressures varying from 60 to $160 \mathrm{~cm} \mathrm{H}_{2} \mathrm{O}$ in steps of $10 \mathrm{~cm} \mathrm{H}_{2} \mathrm{O}$. We assessed the closure properties of the urethral model by applying increasing bladder pressure values and simultaneously recording the flow rate at three cuff pressures (i.e. 60,100 and $140 \mathrm{~cm} \mathrm{H}_{2} \mathrm{O}$ ) using the Critikon-cuff.

\section{Leak point pressure}

In order to measure LPP, we connected one side of the model to a water column representing the bladder. The water level in this column was kept constant using a floating device. At each cuff pressure we increased the water level in steps of $1 \mathrm{~cm} \mathrm{H}_{2} \mathrm{O}$ from $0 \mathrm{~cm} \mathrm{H}_{2} \mathrm{O}$ up to the pressure at which the model showed leakage. This leakage was, conform common clinical practice, visually detected. The corresponding water level was noted as LPP.

\section{Urethral pressure profilometry}

We measured UPP of the model urethra using the perfusion method [23]. We used a 5F catheter with an end-hole [3] commonly used in our clinic. The perfusion fluid used was demineralised water. The catheter was withdrawn through the model by a retractor, driven by a urodynamic measurement unit (Menuet, Dantec Dynamics, Bristol, UK), at four different withdrawal rates $(0.5,1,2$ and $4 \mathrm{~mm} / \mathrm{s})$. We maintained a constant perfusion rate through the catheter with an infusion pump (B. Braun Melsungen AG, Melsungen, Germany) and applied five different perfusion rates $(0.5,1,2,5$ and $10 \mathrm{ml} / \mathrm{min}$ ). At a t-connector between infusion pump 
and catheter we recorded the pressure needed to maintain a constant perfusion rate using a disposable pressure transducer. The measured pressure was recorded on a computer using an A/D-converter (BNC-2110, National Instruments, Woerden, The Netherlands) in combination with a selfwritten Labview-program (National Instruments, Woerden, The Netherlands). For each of the three types of pressure zone we recorded one pressure profile at each combination of cuff pressure, perfusion rate and withdrawal rate. Each profile was corrected for pressure loss caused by the resistance of the catheter. At each of the five different perfusion rates this pressure loss was measured with the catheter outside the model [24]. MUCP was calculated from the corrected pressure profile as the maximum recorded pressure using self-written Matlab ${ }^{\circledR}$-programs. During the UPP measurements no column of water was connected to the model and therefore the bladder pressure was set to zero.

\section{Statistical analysis}

We tested the dependence of LPP on type of pressure zone using analysis of variance (ANOVA). Similarly the dependence of MUCP on type of pressure zone, perfusion rate and withdrawal rate of the catheter was tested. For each combination of pressure zone, perfusion rate and withdrawal rate we tested the relation between MUCP and LPP using Pearson's correlation coefficient and performed linear regression on MUCP as a function of LPP. We compared the slope of each linear function statistically to the ideal slope of 1 using a Student's $t$-test.

\section{Results}

Pressure-flow measurements for the assessment of the closure properties of the model are presented in Fig. 2. The flow rate was found to increase with increasing bladder pressure and the pressure-flow curve was found to be at higher pressure-values for higher cuff pressure. Extrapolation of the curves towards zero flow rate clearly indicates non-zero closure pressure of the model.

LPP increased with increasing cuff pressure in the three cuff types (see Fig. 3). The measured LPP-values were not statistically dependent (ANOVA, $P=0.797$ ) on the type of pressure zone. The LPP-value, however, did not equal the applied cuff pressure. An initial pressure was necessary for the cuff to contact the urethral model. At increasing cuff pressure this phase was followed by adaptation of the cuff to the urethral model in order to achieve 'full contact'. After this point had been reached LPP was found to linearly increase with increasing cuff pressure with a slope of one [25].

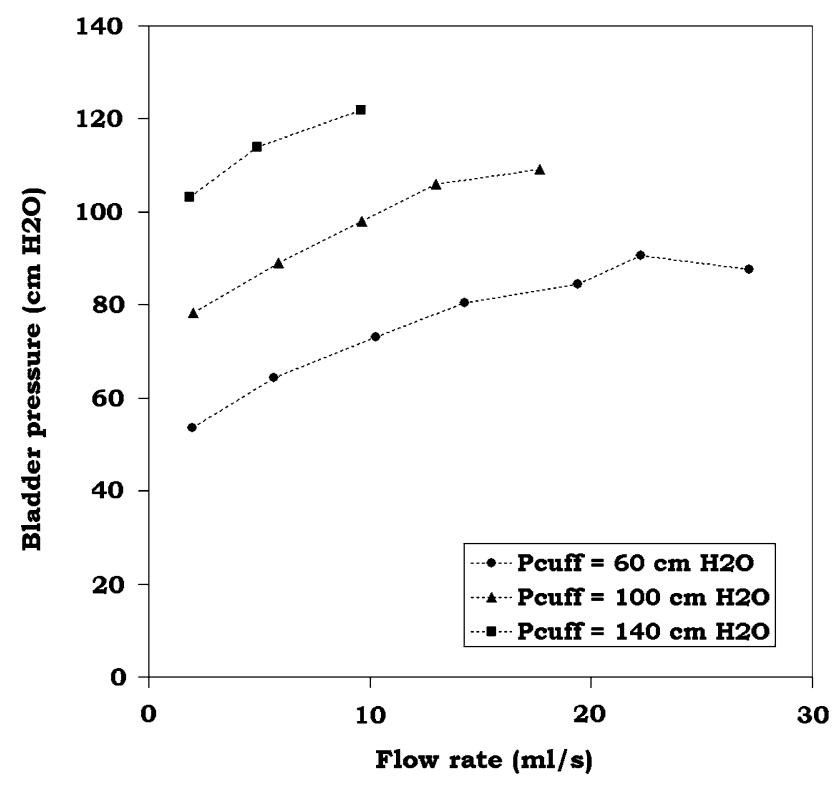

Fig. 2 Pressure-flow measurements in the urethral model using the Tricomed cuff at pressures of 60, 100 and $140 \mathrm{~cm} \mathrm{H}_{2} \mathrm{O}$. Extrapolation of the data-points to zero flow rate zero suggests a realistic non-zero closure pressure, increasing with cuff pressure

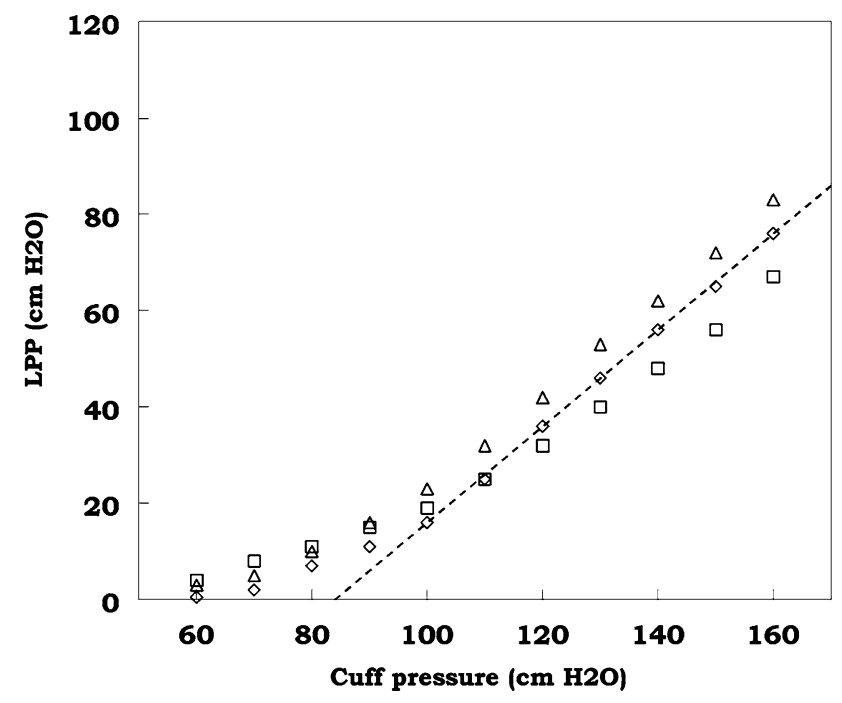

Fig. 3 LPP as a function of the applied cuff pressure for the different cuff-types (indicated as: diamond = single Tricomed-cuff, square = double Tricomed-cuff and triangle $=$ Critikon-cuff). The dotted line represents the linear function fitted to LPP in the single Tricomed-cuff (at cuff pressures between 100 and $160 \mathrm{~cm} \mathrm{H}_{2} \mathrm{O}$ ) with a slope of one

Examples of UPP-recordings in the urethral model are shown in Fig. 4. These profiles were recorded at (a) two different perfusion rates, (b) two different withdrawal rates and (c) three different pressure zones. MUCP was higher at higher perfusion rate and lower at higher withdrawal rate. The types of pressure zone had different effective lengths of pressure-plateaus. MUCP depended significantly on the 

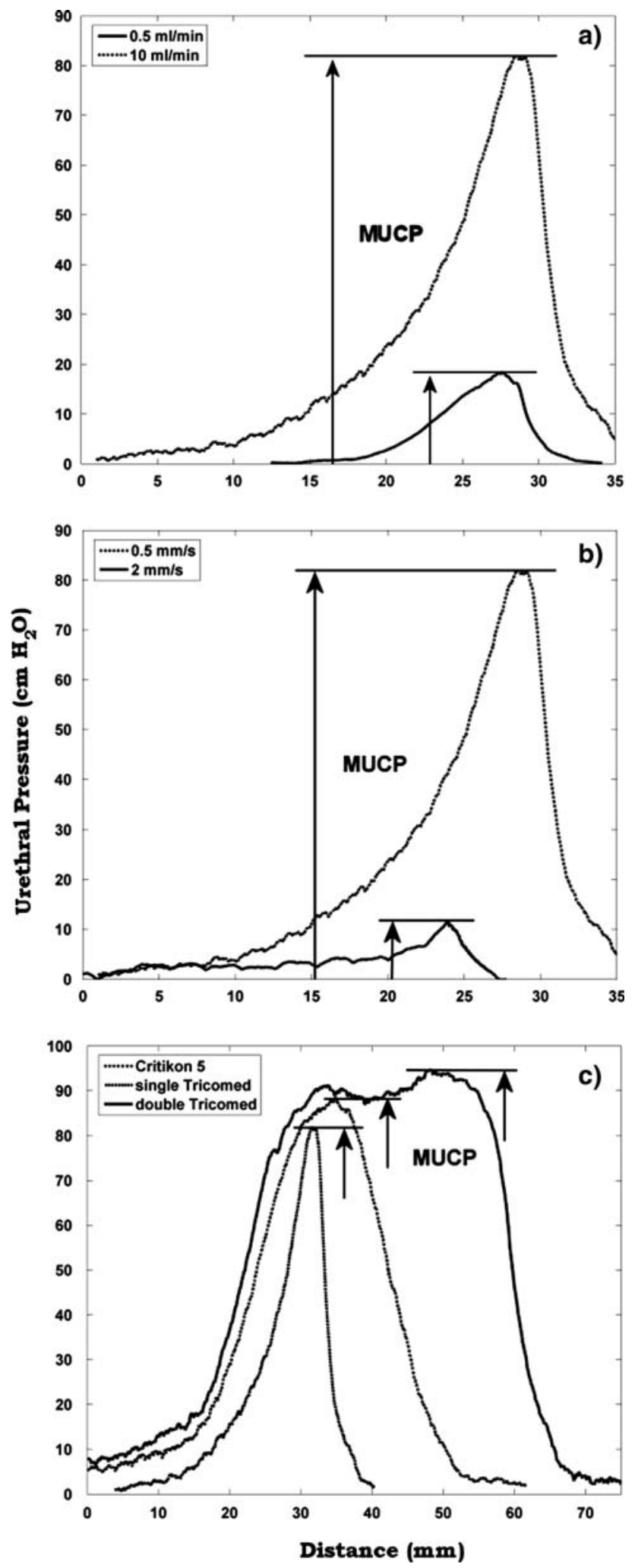

type of pressure zone, perfusion rate, withdrawal rate (ANOVA, $P<0.01$ ) and on the interaction between pressure zone and withdrawal rate (ANOVA, $P<0.05)$.
Fig. 4 Examples of UPP-recordings at a cuff pressure of $150 \mathrm{~cm} \mathrm{H}_{2} \mathrm{O}$. The recordings were done with: a a constant withdrawal rate $(0.5 \mathrm{~mm} /$ s) in combination with two different perfusion rates and $\mathbf{b}$ a constant perfusion rate $(10 \mathrm{ml} / \mathrm{min})$ in combination with two different withdrawal rates using the single Tricomed-cuff. In $\mathbf{c}$ the recordings were done with a constant withdrawal rate $(0.5 \mathrm{~mm} / \mathrm{s})$ and a constant perfusion rate $(10 \mathrm{ml} / \mathrm{min})$ using the three different cuff-types. The horizontal axis represents distance measured from the proximal end of the model urethra

Figure 5 shows MUCP: (a) as function of perfusion rate at four different withdrawal rates and (b) as function of withdrawal rate at five different perfusion rates; all data were measured using the Critikon-cuff at maximum cuff pressure $\left(160 \mathrm{~cm} \mathrm{H}_{2} \mathrm{O}\right)$. With increasing perfusion rate MUCP increased and with increasing withdrawal rate it decreased. This behaviour was also observed using the two other types of pressure zone and at lower cuff-pressures.

Figure 6 shows an example of a linear function fitted to MUCP as a function of LPP. Pearson's correlation coefficient of the linear fits ranged from 0.94 to 1 . For most combinations of perfusion and withdrawal rate the slope of the linear functions was significantly different from 1 $(P<0.05)$. The combinations of perfusion and withdrawal rate for which the slope was not significantly different from 1 for the single Tricomed cuff were: $5 \mathrm{ml} / \mathrm{min}$ and $0.5 \mathrm{~mm} / \mathrm{s}$ $(P=0.115), \quad 10 \mathrm{ml} / \mathrm{min}$ and $0.5 \mathrm{~mm} / \mathrm{s} \quad(P=0.212)$ and $10 \mathrm{ml} / \mathrm{min}$ and $1 \mathrm{~mm} / \mathrm{s}(P=0.164)$. For the double Tricomed cuff: $0.5 \mathrm{ml} / \mathrm{min}$ and $0.5 \mathrm{~mm} / \mathrm{s}(P=0.083)$ and $1 \mathrm{ml} /$ min and $1 \mathrm{~mm} / \mathrm{s}(P=0.446)$. And for the Critikon cuff: $10 \mathrm{ml} / \mathrm{min}$ and $0.5 \mathrm{~mm} / \mathrm{s}(P=0.081)$.

\section{Discussion}

The increase in flow rate with bladder pressure and extrapolation of the pressure-flow curves to a zero flow rate suggests a realistic non-zero closure pressure of the urethral model, which increases with increasing cuff pressure. Therefore our urethral model can be described as a distensible model [26]. In our model LPP was not equal to the applied cuff pressure, but increased linearly with the cuff pressure above a certain threshold pressure. This threshold was probably due to flexible properties of the system, e.g. compressibility of the PVA and extensibility of the blood pressure cuffs. When the cuff is pressurized part of the pressure is balanced by tension in its wall, resulting in a lower pressure exerted upon the wall of the model urethra. Also the model itself may exert a counter pressure due to its compressibility. In spite of this loss of pressure due to the flexible properties of the system LPP did increase linearly above the threshold, so that it may be concluded that LPP adequately reflected the urethral resistance. This was independent of the type of pressure zone. 

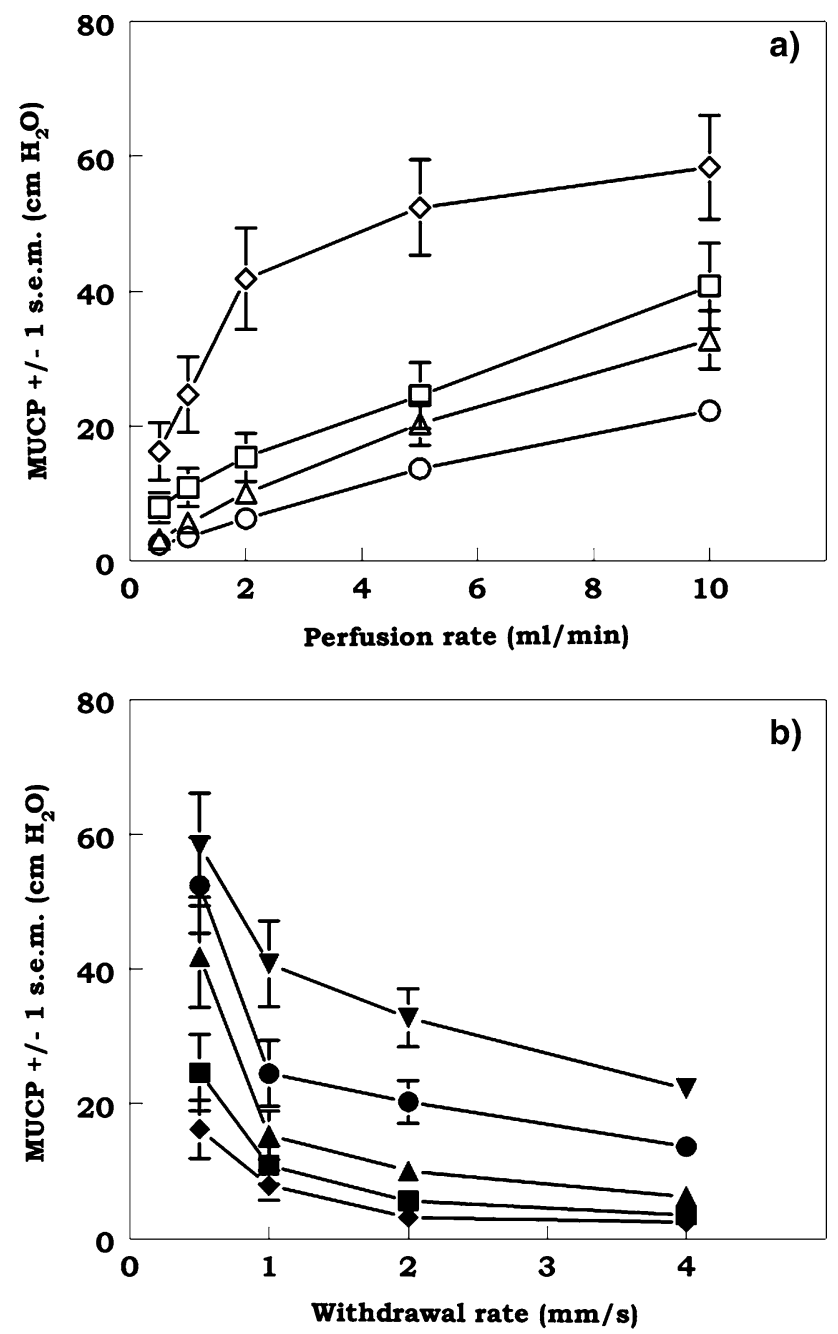

Fig. 5 a MUCP as a function of the perfusion rate for four different withdrawal rates (indicated as: diamond $=0.5 \mathrm{~mm} / \mathrm{s}$, square $=1 \mathrm{~mm} / \mathrm{s}$, triangle $=2 \mathrm{~mm} / \mathrm{s}$ and circle $=4 \mathrm{~mm} / \mathrm{s}$ ). MUCP was recorded using a Critikon cuff at a cuff pressure of $160 \mathrm{~cm} \mathrm{H}_{2} \mathrm{O}$. b MUCP as a function of withdrawal rate for five different perfusion rates (indicated as: filled diamond $=0.5 \mathrm{ml} / \mathrm{min}$, filled square $=1 \mathrm{ml} / \mathrm{min}$, filled triangle $=2 \mathrm{ml} /$ $\mathrm{min}$, filled circle $=5 \mathrm{ml} / \mathrm{min}$ and filled inverted triangle $=10 \mathrm{ml} / \mathrm{min}$ )

Urethral pressure recordings in the urethral model (see Fig. 4) showed much similarity with recordings done in patients. MUCP, however, depended significantly on perfusion rate, withdrawal rate and pressure zone. Increasing the perfusion rate resulted in an increase of MUCP and increasing the withdrawal rate resulted in a decrease of MUCP. MUCP and LPP correlated very well in each set of cuff pressures. However, the slope of the linear regression was only in a limited number of cuff pressure sets comparable to 1. MUCP therefore only accurately corresponded with LPP at a limited number of combinations of perfusion and withdrawal rate. Either the perfusion rate had to be high $(10 \mathrm{ml} /$ $\mathrm{min})$ or the withdrawal rate had to be low $(0.5 \mathrm{~mm} / \mathrm{s})$. The different perfusion rates used in the literature [8-12] could account for the meager correlation between MUCP and

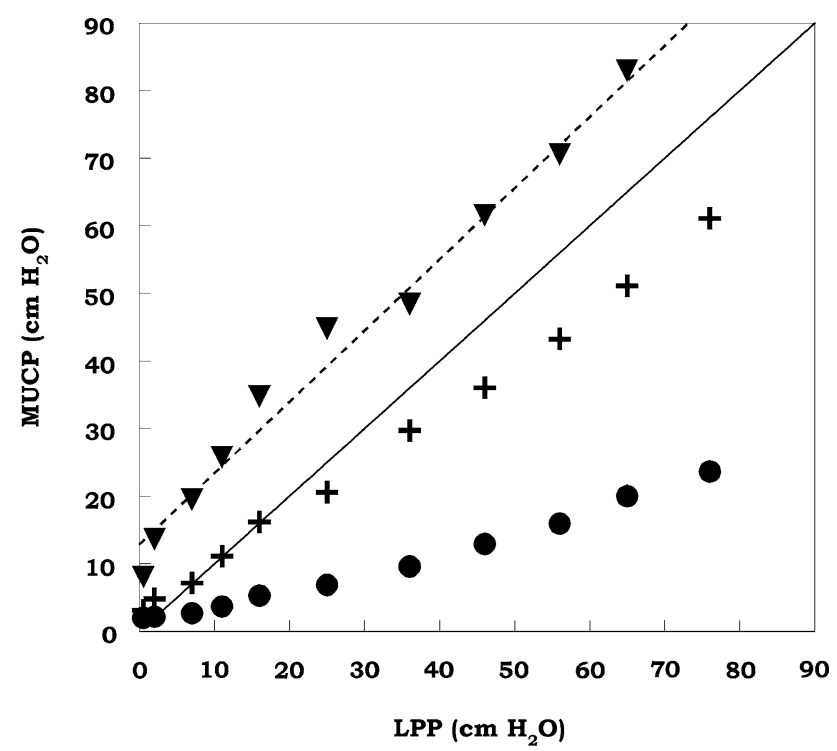

Fig. 6 MUCP as a function of LPP measured in the single Tricomed cuff at a withdrawal rate of $0.5 \mathrm{~mm} / \mathrm{s}$ and three different perfusion rates (filled circle $=0.5 \mathrm{ml} / \mathrm{min}$, plus $=2 \mathrm{ml} / \mathrm{min}$ and filled inverted triangle $=10 \mathrm{ml} / \mathrm{min}$ ). The dotted line represents a linear function, fitted to MUCP values measured with a perfusion rate of $10 \mathrm{ml} / \mathrm{min}$, with a slope not significantly different from 1 . The solid line represents MUCP equal to LPP

LPP [13-15]. The perfusion and withdrawal rate that we found are larger and smaller, respectively, than the rates found by Asmussen [27]. This difference may have been caused by differences in model urethras used. The nature of the relation between MUCP and perfusion and withdrawal rate, however, was practically the same.

The observed dependence of MUCP on perfusion and withdrawal rate can be explained from the basic principle of UPP. To measure pressure in the urethra a pressure-equilibrium needs to be established at the tip of the catheter that reflects this pressure. However, it takes time (i.e. response time of the system) to reach this pressure-equilibrium, the perfusion fluid has to open the urethral lumen at the tip of the catheter to the level where wall stress balances pressure exerted by the fluid. When the time-span in which the catheter passes the high-pressure zone is smaller than the time it takes to reach the pressure-equilibrium the measured MUCP underestimates urethral pressure. The perfusion rate of the catheter and the volume of the urethra determine the response time; the withdrawal rate and the length of the high-pressure zone determine the time-span of passage. Consequently for a realistic pressure profile the combination of perfusion and withdrawal rate should result in a response time smaller than or equal to the time-span in which the catheter passes the high-pressure zone.

The increase in MUCP with increasing perfusion rate contrasts with the absence of, or only slight dependence on, perfusion rates between 2 and $10 \mathrm{ml} / \mathrm{min}$ found by Abrams [28] 
in patients. They did find a dependence at rates $<2 \mathrm{ml} / \mathrm{min}$. Martin and Griffiths [29] ascribed the dependence at $<2 \mathrm{ml} /$ min to imperfect sealing of the catheter by their model, so that at low perfusion rates fluid was able to escape through small leaks at pressures lower than that exerted by the applied obstruction. This may also have been the case in our urethral model, as MUCP, extrapolated from the data in Fig. 2, is higher then the corresponding LPP in Fig. 3. It could be said that a 'measure' for leakage in our model is the 'leak rate' being smaller than $2 \mathrm{ml} / \mathrm{min}$. Probably this leakage occurred at all perfusion rates, but with increasing perfusion rate the pressure loss became relatively less important.

Our PVA model urethra is used as a static approximation of the urethra in vivo. The viscoelastic properties of the model urethra have been tuned to those of the male pig urethra in vitro [22]. One of the main differences between the model and the urethra in vivo is that the model urethra cannot contract, as muscular components have not been included. The dynamic viscoelastic properties caused by muscle contraction in the urethra in vivo could lead to different pressure values. This could contribute to the meager correlation between MUCP and LPP found in patients [13-15]. Additionally, when applying the current model results to clinical use of UPP it should be considered that the optimal combination of perfusion and withdrawal rate in the model urethra might not give the most accurate results in the human situation. This could possibly be caused by a difference in urethral calibre between the model urethra and the human urethra. Future measurements using adapted urethral models with different calibres could reflect the natural variation in human urethral calibre. Furthermore, our model is about three times as long as the female urethra ( $\pm 4 \mathrm{~cm}$ in length). However, we do not expect this difference in length to affect the pressure recordings, since LPP at zero cuff pressure was approximately zero, see Fig. 3. Despite these drawbacks of the model we think our main conclusions are valid for clinical UPP and LPP measurements: MUCP increased with urethral resistance but strongly depends on the perfusion and withdrawal rate of the catheter as well as the type of pressure zone. In a clinical setting, therefore, perfusion and withdrawal rate need to be carefully chosen and standardized. LPP, on the other hand, increases linearly with urethral resistance and did not depend on the type of pressure zone.

Acknowledgment This research was supported by the Technology Foundation STW, applied division of the Netherlands Organization for Scientific Research (NWO) and the technology programme of the Ministry of Economic Affairs.

\section{References}

1. Abrams P, Cardozo L, Fall M et al (2002) The standardisation of terminology of lower urinary tract function: report from the
Standardisation Sub-committee of the International Continence Society. Neurourol Urodyn 21(2):167-178

2. Bruskewitz R, Raz S (1979) Urethral pressure profile using microtip catheter in females. Urology 14(3):303-307

3. Griffiths DJ (1985) The pressure within a collapsed tube, with special reference to urethral pressure. Phys Med Biol 30(9):951-963

4. Anderson RS, Shepherd AM, Feneley RCL (1983) Microtransducer urethral profile methodology: variations caused by transducer orientation. J Urol 130:727-731

5. Schafer W (2001) Some biomechanical aspects of continence function. Scand J Urol Nephrol Suppl 207:44-60; discussion 10625

6. Abrams P, Cardozo L, Khoury S et al (eds) (2005) Incontinence: basics and evaluation, chap 11, vol 1. Health Publication Ltd, Plymouth

7. Weber AM (2001) Is urethral pressure profilometry a useful diagnostic test for stress urinary incontinence? Obstet Gyneacol Surv 56(11):720-735

8. Shawer M, Brown M, Sutherst JR (1983) Comparative examination of female urethral pressure profiles measured by $\mathrm{CO}_{2}$ and $\mathrm{H}_{2} \mathrm{O}$ infusion techniques. Br J Urol 55(3):326-331

9. Hanzal E, Berger E, Koelbl H (1991) Reliability of the urethral closure pressure profile during stress in the diagnosis of genuine stress incontinence. Br J Urol 68(4):369-371

10. Meunier P, Mollard P (1978) Urethral pressure profile in children: a comparison between perfused catheters and micro-transducers, and a study of the usefulness of urethral pressure profile measurements in children. J Urol 120(2):207-210

11. De Haas D, Steinberg PJ, Klopper PJ (1989) Qualitative analysis of the four-channel, high-resolution urethral pressure profile of the female dog. J Urol 142(3):855-859

12. Carnaille BM, Rigot JM, Bailleul JP et al (1992) Urodynamics in patients with pheochromocytoma: a peri-operative study of 10 cases. World J Surg 16(4):676-679

13. McLennan MT, Melick CF, Bent AE (2000) Leak-point pressure: clinical application of values at two different volumes. Int Urogynecol J Pelvic Floor Dysfunct 11(3):136-141

14. Feldner PC Jr, Bezerra LR, de Castro RA et al (2004) Correlation between valsalva leak point pressure and maximal urethral closure pressure in women with stress urinary incontinence. Int Urogynecol J Pelvic Floor Dysfunct 15(3):194-197

15. Nager CW, Schulz JA, Stanton SL et al (2001) Correlation of urethral closure pressure, leak-point pressure and incontinence severity measures. Int Urogynecol J Pelvic Floor Dysfunct 12(6):395-400

16. Baessler K, Miska K, Draths R et al (2005) Effects of voluntary pelvic floor contraction and relaxation on the urethral closure pressure. Int Urogynecol J 16:187-191

17. Theofrastous JP, Cundiff GW, Harris RL et al (1996) The effect of vesical volume on Valsalva leak-point pressures in women with genuine stress urinary incontinence. Obstet Gynecol 87(5 Pt 1):711-714

18. Faerber GJ, Vashi AR (1998) Variations in Valsalva leak point pressure with increasing vesical volume. J Urol 159(6):1909-1911

19. Decter RM, Harpster L (1992) Pitfalls in determination of leak point pressure. J Urol 148(2 Pt 2):588-591

20. Nguyen JK, Gunn GC, Bhatia NN (2002) The effect of patient position on leak-point pressure measurements in women with genuine stress incontinence. Int Urogynecol J Pelvic Floor Dysfunct 13(1):9-14

21. Idzenga T, Pel JJM, Baldewsing RA et al (2005) Perineal noise recording as a non-invasive diagnostic method of urinary bladder outlet obstruction: a study in polyvinyl alcohol and silicone model urethras. Neurourol Urodyn 24(4):381-388

22. Idzenga T, Pel JJM, Mastrigt RV (2006) A biophysical model of the male urethra: comparing viscoelastic properties of polyvinyl alcohol urethras to male pig urethras. Neurourol Urodyn 25(5):451-460 
23. Brown M, Wickham JEA (1969) The urethral pressure profile. Br J Urol 41(2):211-217

24. Abrams P, Blaivas JG, Stanton SL et al (1988) The standardisation of terminology of lower urinary tract function. Scand J Urol Nephrol Suppl 114:5-19

25. Idzenga T, Pel JJM, Mastrigt RV (2005) Leak point pressure or urethral pressure profilometry? Urodynamic evaluation of continence tested in a model urethra. In: International continence society 35 th annual meeting, Montreal, Canada

26. Griffiths DJ (1980) Urodynamics. The mechanics and hydrodynamics of the lower urinary tract. In: Medical physics handbooks, vol 4. Hilger, Bristol
27. Asmussen M (1976) Intraurethral pressure recording. A comparison betwen tip-transducer catheters and open-end catheters with constant flow. Scand J Urol Nephrol 10(1):1-6

28. Abrams PH, Martin S, Griffiths DJ (1978) The measurement and interpretation of urethral pressures obtained by the method of Brown and Wickham. Br J Urol 50(1):33-38

29. Martin S, Griffiths DJ (1976) Model of the female urethra: part 1static measurements of pressure and distensibility. Med Biol Eng 14(5):512-518 